\title{
Performance of a High-Fidelity 4kW-Class Engineering Model PPU and Integration with HiVHAc System
}

\author{
Luis R. Piñero ${ }^{1}$ and Hani Kamhawi ${ }^{2}$ \\ NASA Glenn Research Center, Cleveland, Ohio, 44135 \\ and \\ Vlad Shilo ${ }^{3}$ \\ Colorado Power Electronics, Inc., Fort Collins, Colorado, 80524
}

\begin{abstract}
The High Voltage Hall Accelerator (HiVHAc) propulsion system consists of a thruster, power processing unit (PPU), and propellant feed system. An engineering model PPU was developed by Colorado Power Electronics, Inc. funded by NASA's Small Business Innovative Research Program. This PPU uses an innovative 3-phase resonant converter to deliver $4 \mathrm{~kW}$ of discharge power over a wide range of input and output voltage conditions. The PPU includes a digital control interface unit that automatically controls the PPU and a xenon flow control module (XFCM). It interfaces with a control computer to receive highlevel commands and relay telemetry through a MIL-STD-1553B interface. The EM PPU was thoroughly tested at GRC for functionality and performance at temperature limits and demonstrated total efficiencies a high as 95 percent. Integrated testing of the unit was performed with the HiVHAc thruster and the XFCM to demonstrate closed-loop control of discharge current with anode flow. Initiation of the main discharge and power throttling were also successfully demonstrated and discharge oscillations were characterized.
\end{abstract}

\section{Introduction}

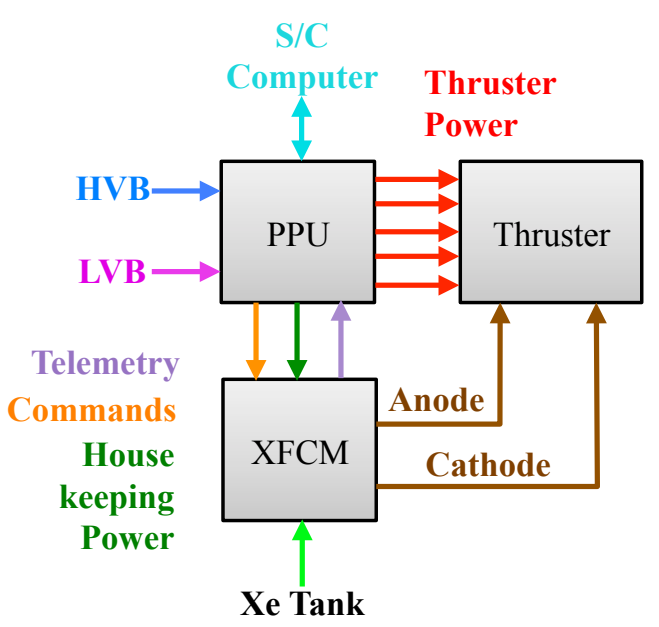

Figure 1. HiVHAc propulsion system and interfaces.
G lectric propulsion is critical for NASA's goals for

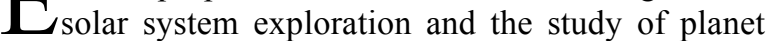
Earth. Many missions can be enabled by state of the art electric propulsion systems and also by systems currently under development. ${ }^{1-3}$ Mission studies have found that a Hall thruster system with high specific impulse can provide substantial cost and performance benefits relative to the other advanced electric propulsion technologies for certain types of NASA's Discovery-Class science missions. ${ }^{4-5}$

NASA Glenn Research Center (GRC) is leading technology development activities for the High Voltage Hall Accelerator (HiVHAc) propulsion system as a lower cost electric propulsion alternative for future cost constrained missions. ${ }^{6-7}$ The HiVHAc propulsion system consist of the $4.0 \mathrm{~kW}$ Hall thruster currently under development at GRC, the power processing unit (PPU) being developed by Colorado Power Electronics, Inc., and the Xenon Flow Control

\footnotetext{
${ }^{1}$ Senior Electrical Engineer, Electric Propulsion Systems Branch, 21000 Brookpark Rd, Associate Fellow

${ }^{2}$ Senior Aerospace Engineer, Electric Propulsion Systems Branch, 21000 Brookpark Rd, Associate Fellow

${ }^{3}$ Principal System Design Engineer, 120 Commerce Way, Non-Member
} 
Module (XFCM) which was developed by VACCO Industries. CPE developed the HiVHAc PPU under the Small Business Innovative Research (SBIR) Program. Four different design iterations with increasing functionality and fidelity have been completed including a breadboard discharge module and two brassboard PPUs. The latest iteration is an engineering model (EM) PPU with flight form and fit and most functionality including a digital control interface unit (DCIU) which automatically controls the entire propulsion system using high-level commands and interfaces with a control (spacecraft) computer. Although the electronic parts used in the EM PPU are commercial-grade, they all have flight equivalents.

The EM PPU was delivered to GRC where it was subjected to functional and performance tests in ambient and vacuum conditions. Integrated testing of the unit was also performed with a VACCO XFCM and the HiVHAc thruster. The main objective of the integration test was to demonstrate closed-loop regulation of discharge current with anode flow control. Also, during the test, discharge current oscillations were characterized to start the optimization process of the discharge output filter. This paper summarizes the results of the EM PPU functional, performance and integration testing.

\section{HiVHAc System Elements}

The HiVHAc system consists of the thruster, PPU, and XFCM as shown in the block diagram in Figure 1. The PPU has high voltage bus (HVB) input that supplies power to the power converters that process power for the thruster. It also has a low voltage bus (LVB) input used for internal housekeeping and to power the XFCM, including valve drivers and transducers, so that it can supply regulated xenon flow to the thruster anode and cathode. The PPU receives commands from the spacecraft computer to operate the entire system and transmits telemetry from both PPU output and the XFCM.

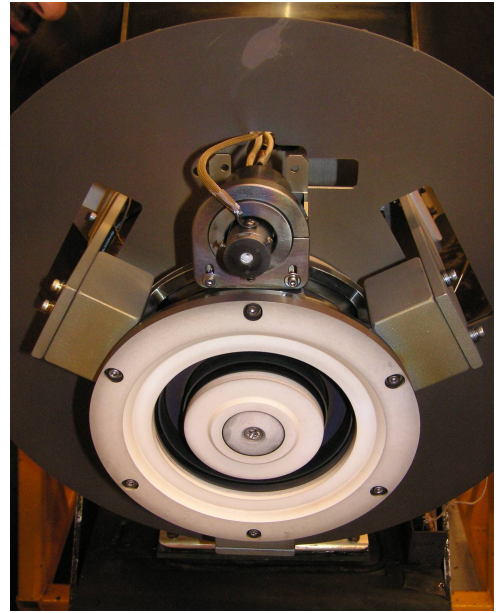

Figure 2. Photograph of the HiVHAc EDU thruster.

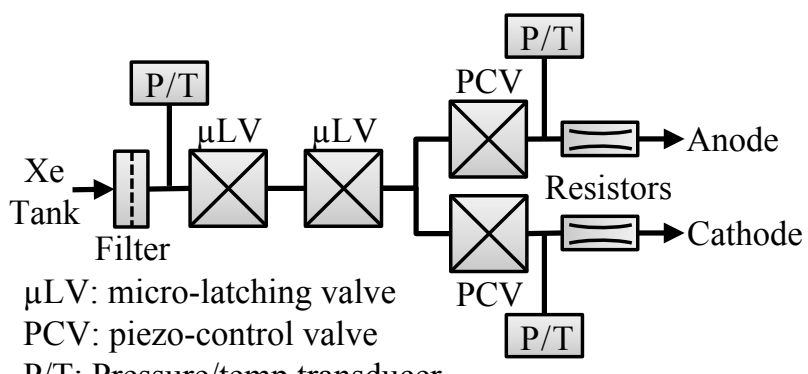

$\mathrm{P} / \mathrm{T}$ : Pressure/temp transducer

Figure 3. VACCO XFCM block diagram.

\section{A. HiVHAc Thruster}

NASA GRC teamed with Aerojet (now AerojetRockedyne) to design, manufacture, and test a HiVHAc engineering development unit (EDU) thruster. The thruster was designed to be throttleable up to $3.9 \mathrm{~kW}$ of power and operate at discharge voltages up to 650 volts. The EDU thruster design incorporates an in-situ discharge channel replacement mechanism to extend thruster life. The EDU thruster has undergone extensive performance tests, thermal characterizations tests, and a random vibration test. ${ }^{8}$ A photograph of the HiHVAc EDU thruster is shown in Figure 2.

\section{B. VACCO XFCM}

The VACCO XFCM was developed as a joint effort between NASA's former In-Space Propulsion Technology Program (ISPT) and the United States Air Force (USAF) as a lightweight propellant flow control alternative for electric propulsion. ${ }^{9}$ A block diagram of the XFCM is shown in Figure 3. It is capable of taking xenon directly from a tank at a pressure range of 20 to 3,000 psia. It regulates flow at a range of 0 to $160 \mathrm{sccm}$ for the anode and cathode through two piezoelectric control valves and passive flow resistors. Two redundant micro-latching valves and input and output pressure and temperature transducers are included from which flow rate can be calculated. The XFCM shown in Figure 4 has a mass of $1.25 \mathrm{~kg}$ and measures 19.5 by 7.0 by $7.5 \mathrm{~cm}$. Flight qualification was completed in June 2012.

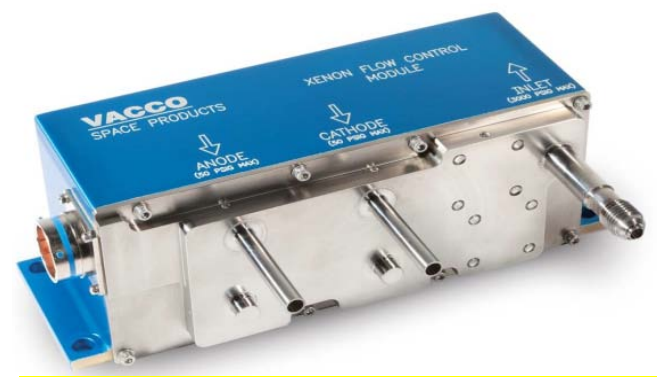

Figure 4. Photograph of the VACCO XFCM 


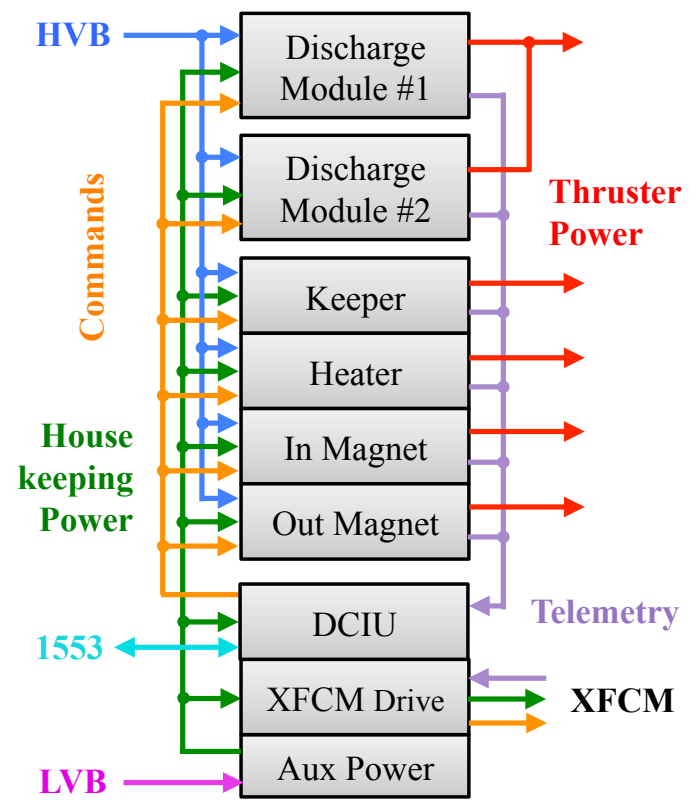

Figure 5. HiVHAc EM PPU block diagram and interfaces.

\section{CPE/HiVHAC EM PPU}

The CPE/HiVHAc EM PPU/DCIU was developed to operate the HiVHAc thruster. Table 1 summarizes the input and output requirements for the EM PPU. This modular PPU consists of four modules including two discharge modules, an ancillary module for the inner magnet, outer magnet, keeper, and heater supplies; and a DCIU module that contain the main DCIU controller board, XFCM driver board and the housekeeping supply. A block diagram of the EM PPU and its electrical interfaces is shown in Figure 5. The EM PPU mass is $15.6 \mathrm{~kg}$ and measures approximately 38.6 by 23.2 by 16.3 $\mathrm{cm}$. A photograph is shown in Figure 6.

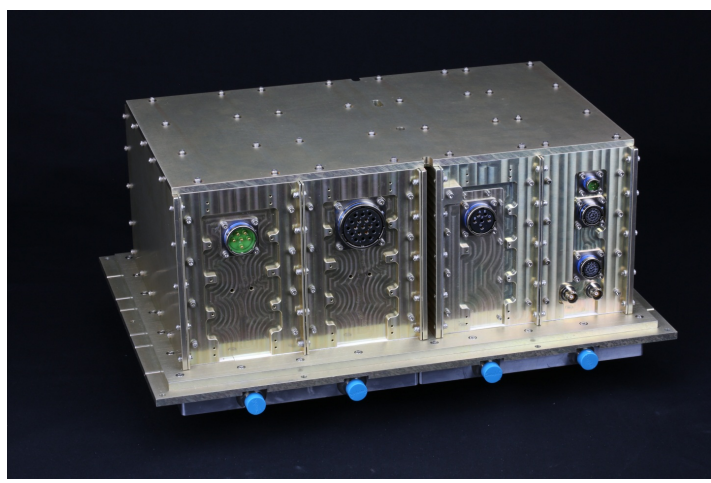

\section{Discharge Modules}

Two discharge modules operate in parallel to provide a total of $4 \mathrm{~kW}$ to the thruster discharge. The

Figure 6. Photograph of the CPE/HiVHAc EM PPU. discharge modules use a 3-phase resonant converter topology capable of supplying full power for any output between 250 and $700 \mathrm{~V}$ at any input voltage level. The 3-phase resonant converter has low switching losses which enables wide range operation and low input and output filter requirements. ${ }^{10}$ The discharge supply can regulate either output voltage or current and has shoot-through protection for the main power transistors. The discharge

\begin{tabular}{|c|c|c|c|c|}
\hline EM PPU & Discharge & Magnets (2) & Keeper & Heater \\
\hline $\begin{array}{c}\text { Output } \\
\text { Voltage }\end{array}$ & $200-700 \mathrm{~V}$ & $2-10 \mathrm{~V}$ & $5-40 \mathrm{~V}$ & $1-15 \mathrm{~V}$ \\
\hline $\begin{array}{c}\text { Output } \\
\text { Current }\end{array}$ & $1.4-15 \mathrm{~A}$ & $1-5 \mathrm{~A}$ & $1-4 \mathrm{~A}$ & $3.5-10 \mathrm{~A}$ \\
\hline $\begin{array}{c}\text { Output } \\
\text { Power Max }\end{array}$ & $4 \mathrm{~kW}$ & $50 \mathrm{~W}$ & $80 \mathrm{~W}$ & $150 \mathrm{~W}$ \\
\hline $\begin{array}{c}\text { Regulation } \\
\text { Mode }\end{array}$ & $\begin{array}{c}\text { Voltage or } \\
\text { Current }\end{array}$ & Current & Current & Current \\
\hline $\begin{array}{c}\text { Output } \\
\text { Ripple }\end{array}$ & \multicolumn{3}{|c}{$\leq 5 \%$} & \\
\hline $\begin{array}{c}\text { Line/Load } \\
\text { Regulation }\end{array}$ & \multicolumn{3}{|c}{$\leq 2 \%$} \\
$\begin{array}{c}\text { Input } \\
\text { Voltage }\end{array}$ & $80-160 \mathrm{~V}$ (main) and $24-34 \mathrm{~V}$ (housekeeping) \\
\hline
\end{tabular}

Table 1. CPE/HiVHAc EM PPU electrical specifications. modules do not have an active master-slave current sharing mechanism but either module can limit power of the other to maintain current sharing.

\section{Ancillary Module}

The ancillary module contains two identical magnet supplies for individual control of inner and outer magnet currents. It contains a keeper and a heater power supply for the cathode. Since all these power converters process significantly less power than the discharge supply, a single-phase resonant converter topology was used. The keeper supply includes a high voltage pulse ignitor for cathode ignition capable of generating a 780 pulse at a rate of approximately $150 \mathrm{~Hz}$. 


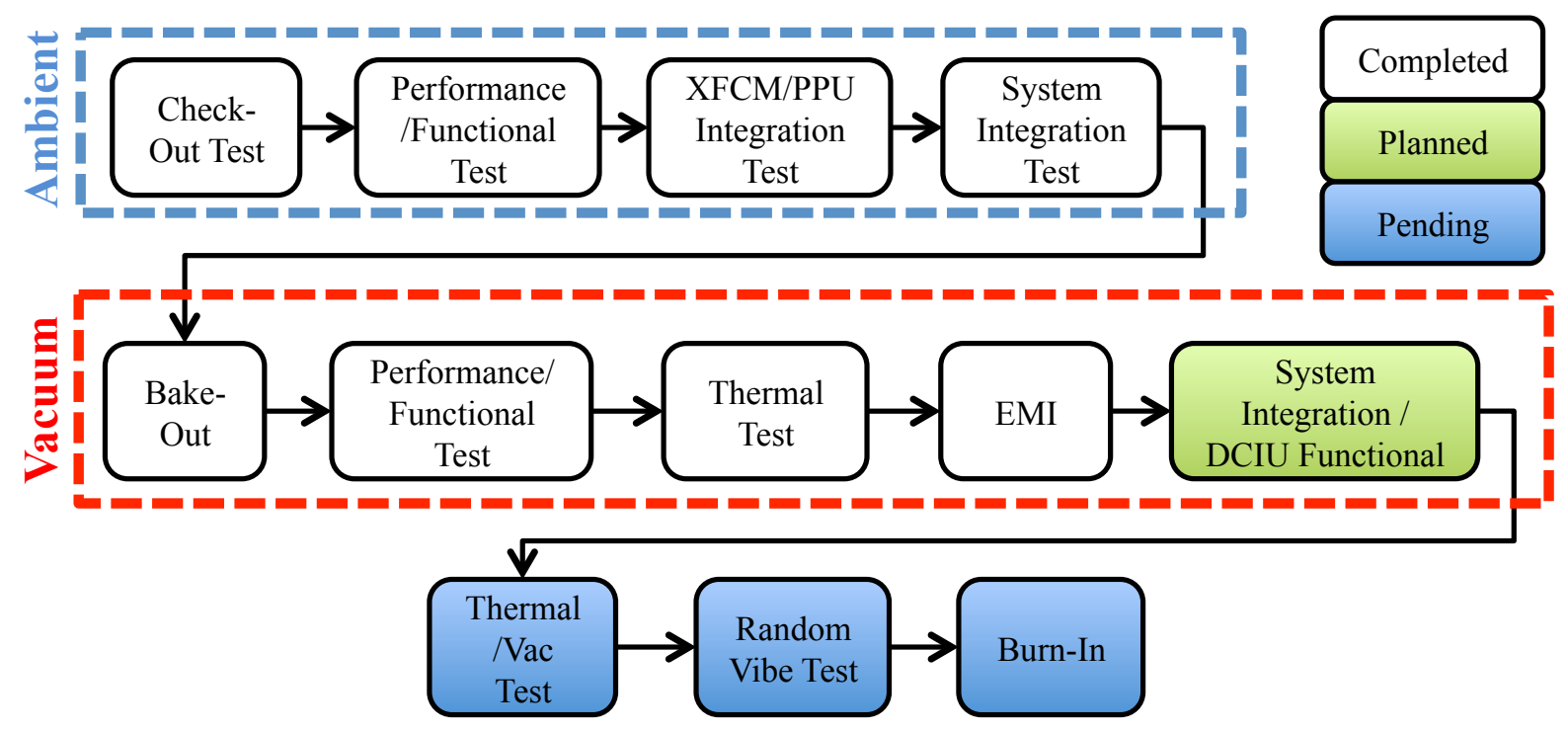

Figure 7. CPE/HiVHAc EM PPU test flow.

\section{DCIU Module}

The DCIU controls the PPU and the XFCM. It transmits telemetry from the PPU outputs and from pressure and temperatures transducers in the XFCM from which xenon flow rate can be calculated. This communication is done through a MIL-STD-1553B interface. The DCIU can control the system in two operating modes. Maintenancemode allows independent enable and setpoint control of all power converters and valves. Auto-mode allows automatic operation of the propulsion system through control sequences to ignite the cathode, start the discharge, steady-state discharge current regulation though anode flow, throttle power up or down, cathode conditioning, and system shutdown. It monitors operation and puts the system into safe mode in case of a fault. Every parameter required for auto-mode operation sequences including thresholds, limits, ramp rates, initial and final values can be selected through the control computer. The DCIU functions are implemented by a field programmable gate array (FPGA). The DCIU module contains the housekeeping supplies that provide bias voltages for internal circuits and isolated power for the XFCM.

\section{Test Description and Results}

\section{A. Test Plan}

A comprehensive test plan was created for the EM PPU. Figure 7 shows the test flow implemented for the PPU. Ambient testing on a resistive load was initially conducted to validate functional and performance requirements and verify that the PPU could operate a thruster. The HiVHAc thruster and $\mathrm{XFCM}$ were installed in vacuum facility 12 (VF12) for integration testing. VF12 is a $3-\mathrm{m}$ diameter by 10 -m long vacuum facility with cryo-panels that can

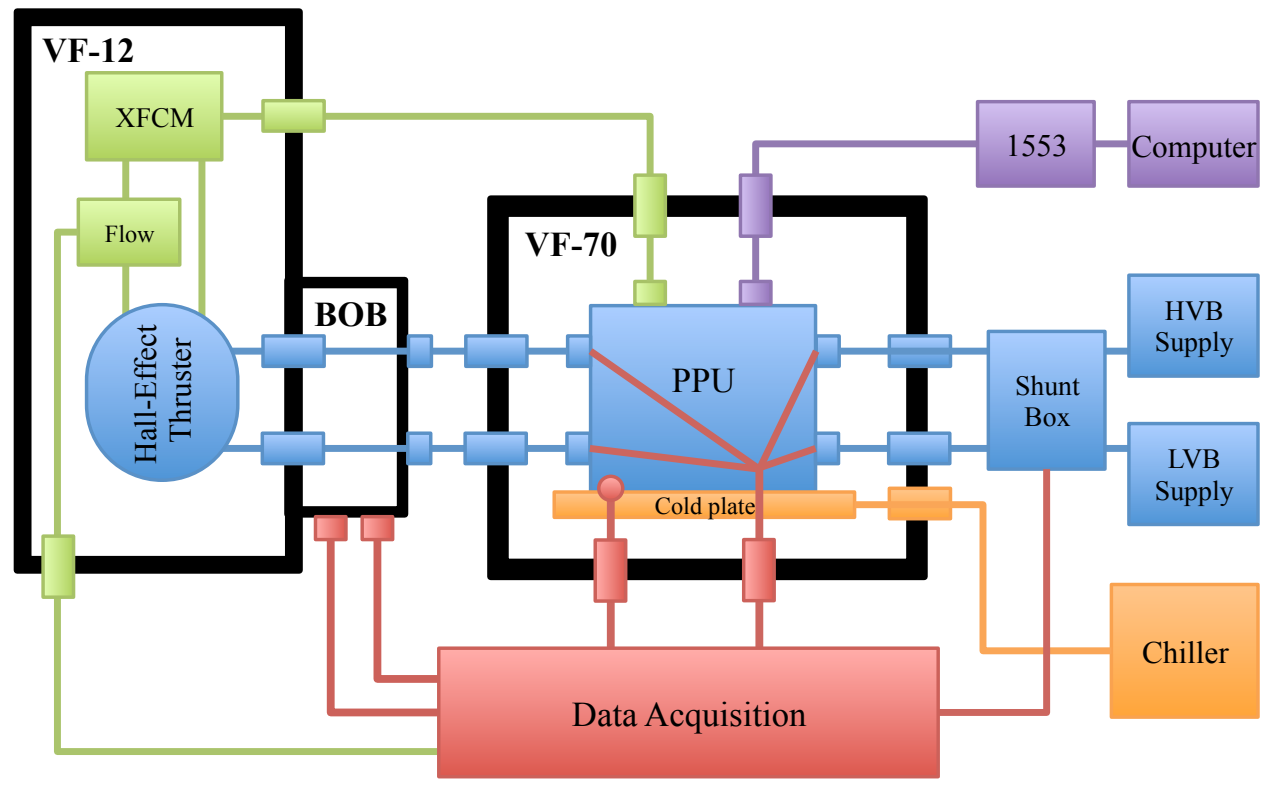

Figure 8. Block diagram of test setup for system integration test. 
maintain background pressure at approximately $1 \times 10^{-6}$ Torr while operating the thruster. After integration testing, the PPU was installed in Vacuum Facility 70 (VF70) mounted on a liquid-cooled baseplate. VF70 is a 0.6-m diameter by $1-\mathrm{m}$ long vacuum chamber located next to VF12 and dedicated to PPU testing. It is capable of operating a PPU at a background pressures lower than $1 \times 10^{-6}$ Torr. The EM PPU was baked-out and then subjected to a vacuum functional and performance test. Then, a thermal test was conducted to measure EM PPU performance at baseplate temperature operational limits of -20 and $50^{\circ} \mathrm{C}$. An electromagnetic interference (EMI) test was also conducted per MIL-STD-461C (CE01 and CE03 requirements) to characterize conducted emissions on both HVB and LVB inputs. This data will be used to optimize input filter performance in the next design iteration of the PPU. All tests were conducted on a resistive load except for system integration tests. Thermal/vacuum, random vibration, and burn-in tests are planned and will be conducted as resources become available and schedule allows.

Table 2. Operating conditions for performance testing on a resistive load.

\begin{tabular}{|c|c|c|c|c|c|c|}
\hline $\begin{array}{c}\text { Discharge } \\
\text { Voltage }\end{array}$ & $\begin{array}{c}\text { Discharge } \\
\text { Current }\end{array}$ & $\begin{array}{c}\text { Magnet } \\
\text { Current }\end{array}$ & $\begin{array}{c}\text { Keeper } \\
\text { Current }\end{array}$ & $\begin{array}{c}\text { Thruster } \\
\text { Power }\end{array}$ & $\begin{array}{c}\text { HVB } \\
\text { Voltage }\end{array}$ & $\begin{array}{c}\text { LVB } \\
\text { Voltage }\end{array}$ \\
\hline $200 \mathrm{~V}$ & $1.4 \mathrm{~A}$ & $2.4 \mathrm{~A}$ & $1.0 \mathrm{~A}$ & $0.31 \mathrm{~kW}$ & $80,120,160 \mathrm{~V}$ & $24,28,34 \mathrm{~V}$ \\
\hline $300 \mathrm{~V}$ & $1.7 \mathrm{~A}$ & $2.9 \mathrm{~A}$ & $1.0 \mathrm{~A}$ & $0.55 \mathrm{~kW}$ & $80,120,160 \mathrm{~V}$ & $28 \mathrm{~V}$ \\
\hline $400 \mathrm{~V}$ & $2.5 \mathrm{~A}$ & $2.8 \mathrm{~A}$ & $1.0 \mathrm{~A}$ & $1.03 \mathrm{~kW}$ & $80,120,160 \mathrm{~V}$ & $28 \mathrm{~V}$ \\
\hline $500 \mathrm{~V}$ & $3.0 \mathrm{~A}$ & $3.7 \mathrm{~A}$ & $1.0 \mathrm{~A}$ & $1.55 \mathrm{~kW}$ & $80,120,160 \mathrm{~V}$ & $28 \mathrm{~V}$ \\
\hline $600 \mathrm{~V}$ & $2.6 \mathrm{~A}$ & $4.0 \mathrm{~A}$ & $1.0 \mathrm{~A}$ & $1.62 \mathrm{~kW}$ & $80,120,160 \mathrm{~V}$ & $28 \mathrm{~V}$ \\
\hline $650 \mathrm{~V}$ & $2.3 \mathrm{~A}$ & $4.0 \mathrm{~A}$ & $1.0 \mathrm{~A}$ & $1.55 \mathrm{~kW}$ & $80,120,160 \mathrm{~V}$ & $28 \mathrm{~V}$ \\
\hline $200 \mathrm{~V}$ & $7.5 \mathrm{~A}$ & $4.0 \mathrm{~A}$ & $1.0 \mathrm{~A}$ & $1.56 \mathrm{~kW}$ & $80,120,160 \mathrm{~V}$ & $28 \mathrm{~V}$ \\
\hline $300 \mathrm{~V}$ & $6.9 \mathrm{~A}$ & $3.5 \mathrm{~A}$ & $1.0 \mathrm{~A}$ & $2.12 \mathrm{~kW}$ & $80,120,160 \mathrm{~V}$ & $24,28,34 \mathrm{~V}$ \\
\hline $400 \mathrm{~V}$ & $7.4 \mathrm{~A}$ & $2.4 \mathrm{~A}$ & $1.0 \mathrm{~A}$ & $2.99 \mathrm{~kW}$ & $80,120,160 \mathrm{~V}$ & $28 \mathrm{~V}$ \\
\hline $500 \mathrm{~V}$ & $7.7 \mathrm{~A}$ & $3.5 \mathrm{~A}$ & $1.0 \mathrm{~A}$ & $3.90 \mathrm{~kW}$ & $80,120,160 \mathrm{~V}$ & $28 \mathrm{~V}$ \\
\hline $600 \mathrm{~V}$ & $6.5 \mathrm{~A}$ & $2.7 \mathrm{~A}$ & $1.0 \mathrm{~A}$ & $3.93 \mathrm{~kW}$ & $80,120,160 \mathrm{~V}$ & $28 \mathrm{~V}$ \\
\hline $650 \mathrm{~V}$ & $5.9 \mathrm{~A}$ & $2.7 \mathrm{~A}$ & $1.0 \mathrm{~A}$ & $3.89 \mathrm{~kW}$ & $80,120,160 \mathrm{~V}$ & $24,28,34 \mathrm{~V}$ \\
\hline
\end{tabular}

\section{B. Test Setup}

A block diagram of the vacuum test setup is shown in Figure 8. The EM PPU was mounted on a liquid-cooled baseplate and installed inside VF70. A recirculating chiller was used to maintain the baseplate temperature. A data acquisition system recorded test data including voltage from sense wires at the PPU input and output connectors, current shunts used to measure input and output currents, and temperatures from 20 thermocouples inside the PPU and the baseplate. The PPU was controlled by a desktop computer through the MIL-STD-1553B interface. Two laboratory power supplies were used to provide input power for the HVB and LVB in the PPU. The setup can be easily switched to operate the resistive load or a thruster and XFCM in VF12. A flow meter was installed to provide a qualitative indicator of xenon flow from the XFCM to the anode during thruster testing.

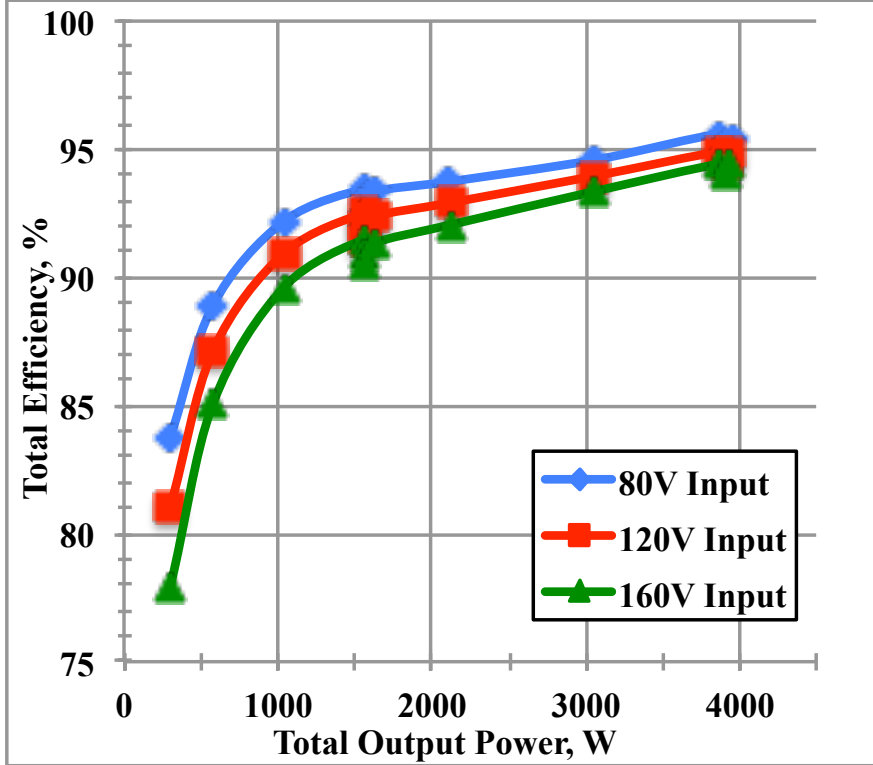

Figure 9. CPE/HiVHAc EM PPU total efficiency as a function of output power. 


\section{EM PPU Functional/Performance Test}

The primary purpose of the functional and performance test was to characterize performance and validate electrical requirements of the EM PPU related to input and output operation ranges, telemetry accuracy, setpoint accuracy, line/load regulation, efficiency, output ripple, and transient response. Performance was measured on resistive load for twelve different throttling conditions that cover the entire throttling range of the HiVHAc thruster and also the entire input voltage range. Table 2 summarizes the operating conditions used for the test.

Total PPU efficiency including the HVB and LVB inputs was measured. Figure 9 shows a plot of total PPU efficiency as a function of power for various input voltage conditions. At full power, efficiency is approximately $95 \%$ and in excess $90 \%$ for any condition above $1 \mathrm{~kW}$. The change in efficiency over the input voltage operation range is approximately 0.5 percent. Results of thermal testing revealed efficiency change of less than $0.5 \%$ for a baseplate temperature variation from 0 to $50^{\circ} \mathrm{C}$ suggesting the PPU has a robust thermal design. Table 3 summarizes the results of other electrical tests. All specifications were met with margin except for the keeper supply telemetry and setpoint accuracy which were marginally exceeded. Improvements for these circuits have been developed and will be implemented in the next design iteration of the PPU.

Table 3. CPE/HiVHAc EM PPU electrical performance.

\begin{tabular}{|c|c|c|c|c|}
\hline & Specification & \multicolumn{2}{|c|}{ Test Results } & Test Conditions \\
\hline \multirow{2}{*}{$\begin{array}{l}\text { Telemetry } \\
\text { Accuracy }\end{array}$} & \multirow{2}{*}{$\leq 2 \%$ of FS } & Discharge $\leq 1.0 \%$ & Keeper $\leq 2.7 \%$ & \multirow{2}{*}{ Over throttling range } \\
\hline & & Magnet $\leq 1.5 \%$ & Heater $\leq 2.0 \%$ & \\
\hline \multirow{2}{*}{$\begin{array}{l}\text { Set point } \\
\text { Accuracy }\end{array}$} & \multirow{2}{*}{$\leq 2 \%$ of FS } & Discharge $<0.1 \%$ & Keeper $\leq 2.5 \%$ & \multirow{2}{*}{ Over throttling range } \\
\hline & & Magnet $\leq 0.8 \%$ & Heater $\leq 1.7 \%$ & \\
\hline \multirow{2}{*}{$\begin{array}{c}\text { Line } \\
\text { Regulation }\end{array}$} & \multirow{2}{*}{$\leq 2 \%$} & Discharge $\leq 0.01 \%$ & Keeper $\leq 3.2 \%$ & \multirow{2}{*}{ Over operating range } \\
\hline & & Magnet $\leq 0.8 \%$ & Heater $\leq 0.7 \%$ & \\
\hline \multirow{2}{*}{$\begin{array}{c}\text { Load } \\
\text { Regulation }\end{array}$} & \multirow{2}{*}{$\leq 2 \%$} & Discharge $\leq 0.05 \%$ & Keeper $\leq 0.8 \%$ & \multirow{2}{*}{ Over operating range } \\
\hline & & Magnet $\leq 0.8 \%$ & Heater $\leq 1.9 \%$ & \\
\hline \multirow{2}{*}{ Efficiency } & \multirow{2}{*}{$\geq 95 \%$ at $\mathrm{FP}$} & Discharge: $86-96 \%$ & Keeper: $47-80 \%$ & \multirow{2}{*}{ Over operating range } \\
\hline & & Magnet: $57-86 \%$ & Heater: $57-87 \%$ & \\
\hline \multirow{2}{*}{$\begin{array}{c}\text { Output } \\
\text { Ripple }\end{array}$} & \multirow{2}{*}{$\leq 5 \%$} & Discharge $\leq 0.7 \%$ & Keeper $\leq 3.3 \%$ & \multirow{2}{*}{ Over operating range } \\
\hline & & Magnet $\leq 0.8 \%$ & Heater $\leq 1.0 \%$ & \\
\hline \multirow{2}{*}{$\begin{array}{l}\text { Transient } \\
\text { Response }\end{array}$} & \multirow{2}{*}{$\mathrm{n} / \mathrm{a}$} & Discharge $\leq 8 \mathrm{~ms}$ & Keeper $\leq 4 \mathrm{~ms}$ & \multirow{2}{*}{ No-load to full power } \\
\hline & & Magnet $\leq 10 \mathrm{~ms}$ & Heater $\leq 8 \mathrm{~ms}$ & \\
\hline $\begin{array}{c}\text { Temperature } \\
\text { Range }\end{array}$ & -20 to $50^{\circ} \mathrm{C}$ & \multicolumn{2}{|c|}{-20 to $50^{\circ} \mathrm{C}$} & \\
\hline
\end{tabular}

\section{System Integration Test}

The main objectives of the system integration test were demonstrating that the EM PPU was capable of controlling the XFCM, starting the thruster discharge, and maintain stable steady-state operation including the ability to maintain constant power operation by regulating discharge current through anode flow. Figure 10 shows a block diagram of the discharge current feedback loop. The discharge current telemetry is compared to a discharge current setpoint $r(t)$ to generate and error signal $e(t)$. This error is then used by a digital PID controller, implemented in the DCIU, to generate the necessary drive voltage $u(t)$ for the anode piezo-control valve in the XFCM to control xenon flow to the thruster and the discharge current. The gain parameters for the PID controller can be adjusted at the control computer to change the loop response. 


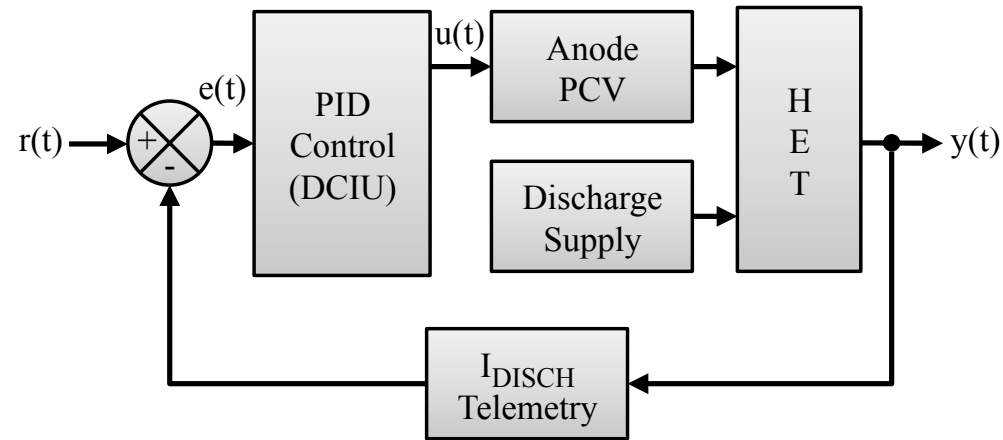

Figure 10. Discharge current closed-loop diagram.
The thruster was started several times using different sequences at a discharge operating condition of $300 \mathrm{~V}$ and approximately $2.5 \mathrm{~A}$. Figures 11 and 12 show the discharge voltage and current, magnet current, and an anode flow rate indicator (uncalibrated) during starting transients. In Figure 11 , at $\mathrm{T}=0 \mathrm{~s}$, the cathode is already ignited, operating off the keeper supply, and the anode piezo-control valve is commanded to open. Anode flow rate starts and at $\mathrm{T}=12 \mathrm{~s}$, the

discharge and magnet supplies are turned on. The discharge current ramps up with approximately $20 \%$ overshoot by $\mathrm{T}=22 \mathrm{~s}$. The PID controller then gradually reduces the anode flow rate and by $\mathrm{T}=60 \mathrm{~s}$ it reaches steady-state. Figure 12 shows a thruster start in glow-mode. At $\mathrm{T}=0 \mathrm{~s}$, the cathode is already ignited, operating off the keeper supply, and the anode piezo-control valve is commanded to open. At $\mathrm{T}=3 \mathrm{~s}$, the discharge and magnet supplies are turned on. Because of higher anode flow, the discharge supply operates in current-mode at the commanded current limit level of $6 \mathrm{~A}$ and a discharge voltage of approximately $75 \mathrm{~V}$. At $\mathrm{T}=7 \mathrm{~s}$, the PID controller reduces the anode flow rate until at $\mathrm{T}=10 \mathrm{~s}$, the discharge supply starts transitioning out of current limit. The discharge voltage reaches steady-state at $\mathrm{T}=15 \mathrm{~s}$ with a $20 \%$ undershoot on anode flow. The discharge current reaches steadystate at approximately $\mathrm{T}=50 \mathrm{~s}$. The over and

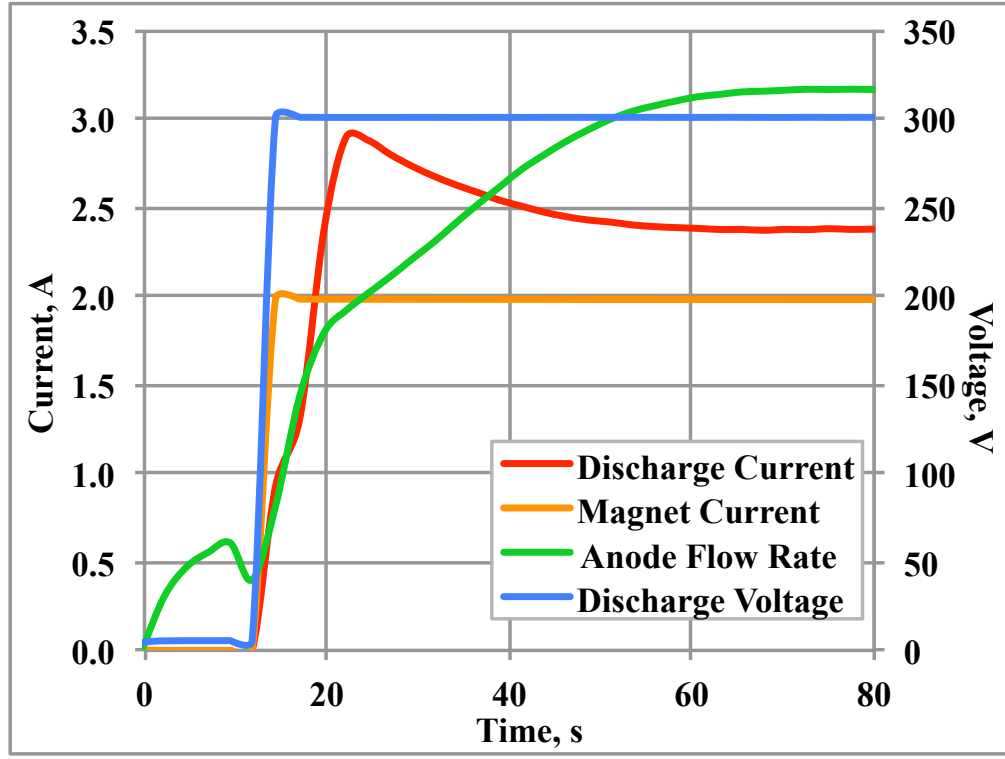

Figure 11. Plot of nominal discharge start transient.

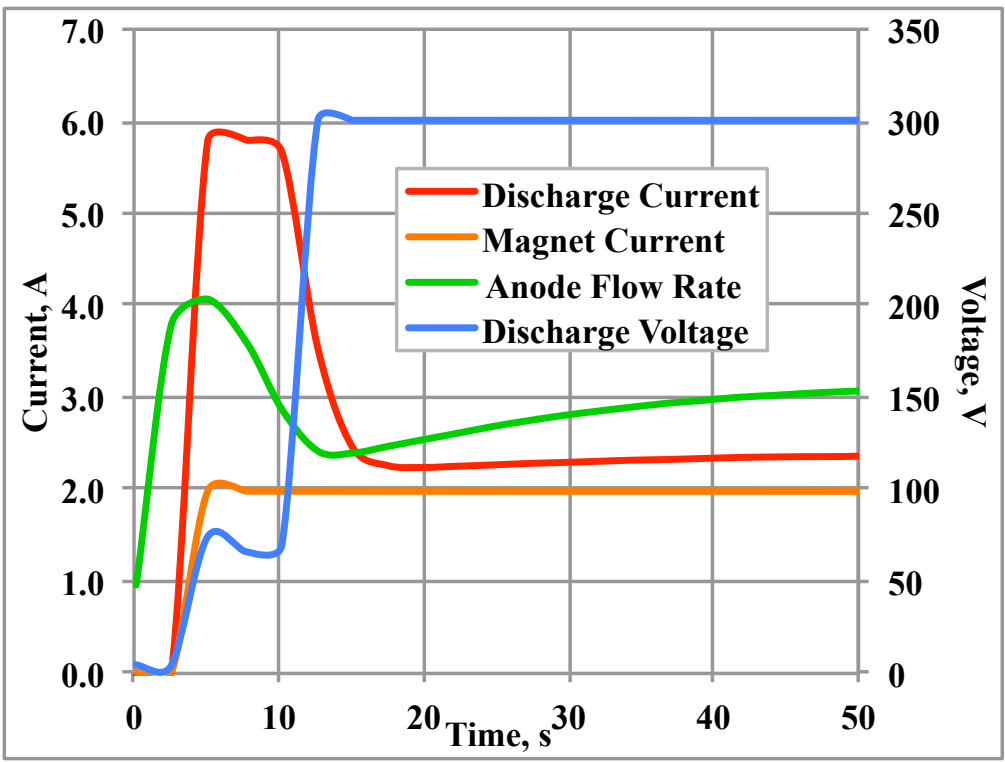

Figure 12. Plot of glow-mode discharge start transient. under shoots during these two ignitions is due to the hysteretic behavior of the piezo-control valve in the XFCM. Further optimization of the ignition is possible by adjusting the PID controller parameters.

The ability of the EM PPU to throttle thruster power up or down was also demonstrated. Figure 13 shows a plot of discharge voltage and current and anode flow rate for a wide throttling profile between 1.5 and $3.9 \mathrm{~kW}$. The thruster was initially operating at discharge conditions of $500 \mathrm{~V}$ and $2 \mathrm{~A}$. The discharge current was incremented in approximately 1 A intervals up to approximately $7 \mathrm{~A}$. Then, the discharge voltage was increased to $600 \mathrm{~V}$ and the discharge current decremented. During this sequence, the discharge current tracks the anode flow as a results of adjustments 
of the PID controller. Small overshoots and undershoots were observed at the transitions between steps because of the hysteresis of the piezo-control valve. Additional testing will be done in the future to optimize transient response of the PID controller.

Discharge oscillations were characterized during integration testing. Figure 14 shows the oscillations observed during full power operation at discharge conditions of $600 \mathrm{~V}$ and $6.5 \mathrm{~A}$. The peakto-peak current oscillations were approximately $3.7 \mathrm{~A}$ at a frequency of approximately $100 \mathrm{kHz}$ which is consistent to previous values.

\section{Future Plans for Prototype Demonstration Unit PPU Development CPE was awarded a Phase III SBIR contract funded by the SBIR Program, ISPT, and the Jet Propulsion Laboratory}

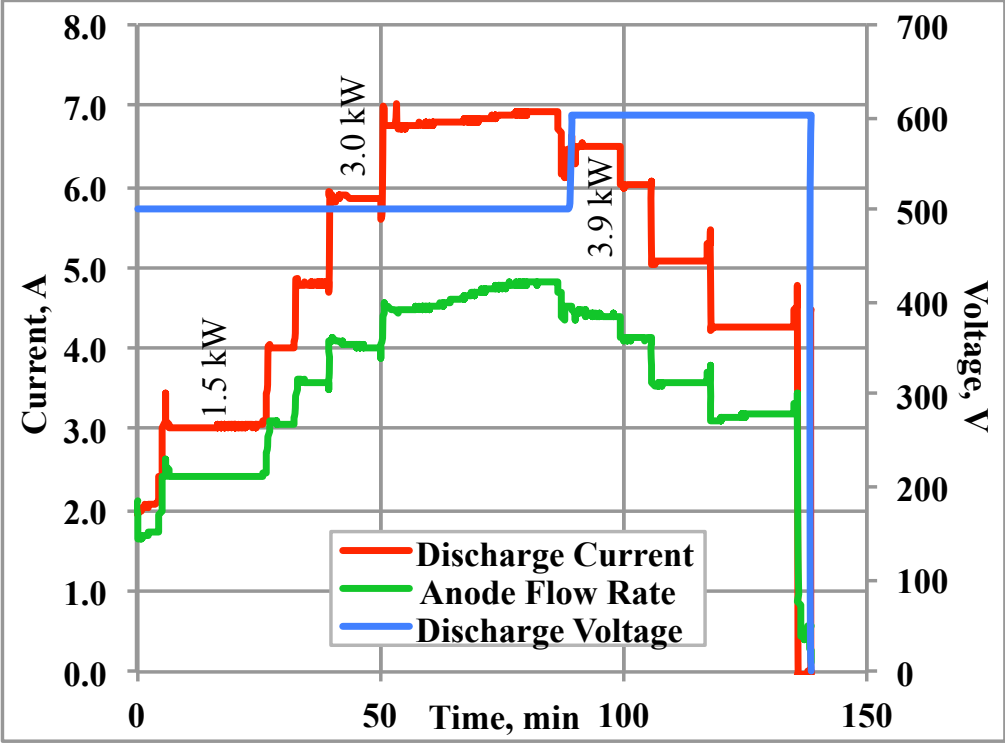

Figure 13. Plot of thruster throttling with discharge current regulation with anode flow. (JPL) to further advance the TRL level of this PPU. The next iteration of this design, designated as prototype development unit (PDU) PPU will be based on the EM PPU design. Some input and output specifications were changed to enable operation of other thrusters and to better satisfy the power requirements of commercial spacecraft busses. Table 4 shows the specifications for the PDU PPU. Text in red shows changes in specifications. The PDU PPU will also add several functionalities like magnet polarity reversal, input telemetry, discharge ripple telemetry, independent discharge module control, heater power and control for XFCM in-line heater for increased operating range, status flags, safety interlocks and lockouts. Also, some issues identified during testing of the EM will be corrected including the keeper telemetry accuracy and some grounding and isolation issues. An FPGA with a radhard flight equivalent will also be used in this unit. The PDU PPU will be subjected to environmental testing to qualification levels and integration testing will be performed at GRC with the other HiVHAc propulsion system components.

\section{Conclusions}

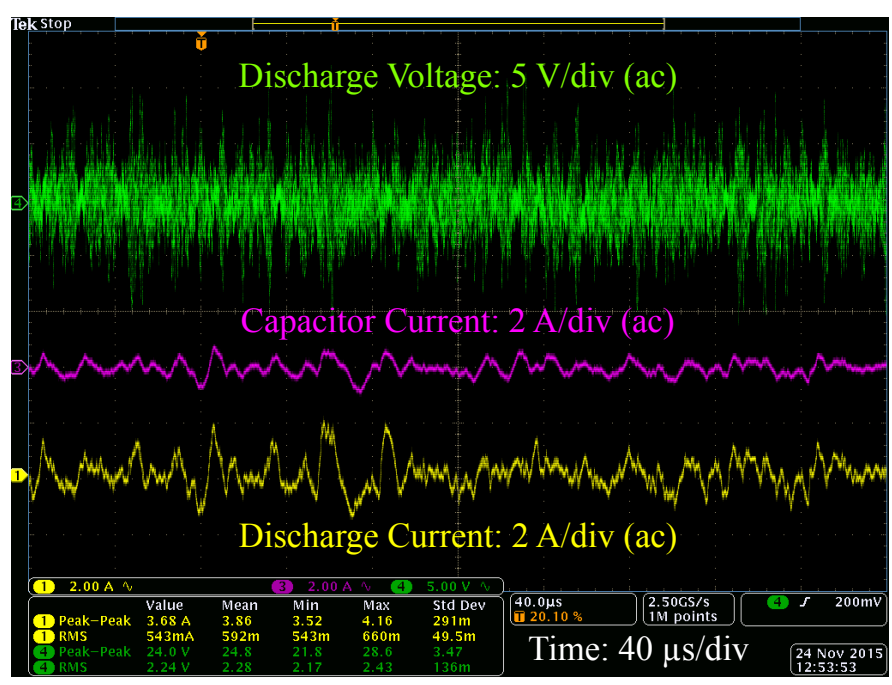

Figure 14. Discharge oscillations during system integration test.
The CPE/HiVHAc EM PPU developed was subjected to a thorough test plan to validate functional and performance requirements. Most electrical requirements were met with margin including total efficiencies as high as $95 \%$. The EM PPU demonstrated the ability to start the HiVHAc thruster using two different starting sequences. It also demonstrated stable closed-loop control of discharge current through anode flow and was successfully throttled up and down in power over a wide range of operating conditions. This testing validates the EM PPU design and reduces the risk for the next design iteration. The PDU PPU will include several changes to input and output specifications to allow operation of other thrusters and better align with NASA mission needs. It will also include additional functionality typically expected in flight Hall thruster systems. Completion of the PDU is expected in late 2018 . 
Table 4. CPE/HiVHAc PDU PPU electrical specifications.

\begin{tabular}{|c|c|c|c|c|}
\hline PDU PPU & Discharge & Magnets (2) & Keeper & Heater \\
\hline $\begin{array}{l}\text { Output } \\
\text { Voltage }\end{array}$ & $200-700 \mathrm{~V}$ & $2-20 \mathrm{~V}$ & $5-40 \mathrm{~V}$ & $1-13 \mathrm{~V}$ \\
\hline $\begin{array}{l}\text { Output } \\
\text { Current }\end{array}$ & $1.4-15 \mathrm{~A}$ & $1-7.5 \mathrm{~A}$ & $1-2 \mathrm{~A}$ & $3.5-21 \mathrm{~A}$ \\
\hline $\begin{array}{c}\text { Output } \\
\text { Power Max }\end{array}$ & $4.5 \mathrm{~kW}$ & $108 \mathrm{~W}$ & $80 \mathrm{~W}$ & $210 \mathrm{~W}$ \\
\hline $\begin{array}{l}\text { Regulation } \\
\text { Mode }\end{array}$ & $\begin{array}{l}\text { Voltage or } \\
\text { Current }\end{array}$ & Current & Current & Current \\
\hline $\begin{array}{l}\text { Output } \\
\text { Ripple }\end{array}$ & \multicolumn{4}{|c|}{$\leq 5 \%$} \\
\hline $\begin{array}{l}\text { Line/Load } \\
\text { Regulation }\end{array}$ & \multicolumn{4}{|c|}{$\leq 2 \%$} \\
\hline $\begin{array}{c}\text { Input } \\
\text { Voltage }\end{array}$ & \multicolumn{4}{|c|}{$68-140 \mathrm{~V}$ (main) and $24-34 \mathrm{~V}$ (housekeeping) } \\
\hline
\end{tabular}

\section{References}

${ }^{1}$ Randolph, T. M., "Qualification of Commercial Electric Propulsion Systems for Deep Space Missions, “ IEPC2007-271, 30 ${ }^{\text {st }}$ International Electric Propulsion Conference, Florence, Italy, September 17-20, 2007.

${ }^{2}$ Hofer, R. R., "High-Specific Impulse Operation of the BPT-4000 Hall Thruster for NASA Science Missions," AIAA-2010-6623, 46 ${ }^{\text {th }}$ AIAA Joint Propulsion Conference \& Exhibit, Nashville, Tennessee, 25 - 28 July 2010.

${ }^{3}$ Snyder, J. S., "Throttled Performance of the SPT-140 Hall Thruster," AIAA-2014-3816, 50 $0^{\text {th }}$ AIAA Joint Propulsion Conference, Cleveland, Ohio, July 28-30, 2014.

${ }^{4}$ Oh, D., "Evaluation of Solar Electric Propulsion Technologies for Discovery Class Missions," 41st AIAA Joint Propulsion Conference, AIAA 2005-4270, Tucson, Arizona, July 2005.

${ }^{5}$ Witzberger, K. E., et al., "NASA's 2004 In-Space Propulsion Re-focus Studies for New Frontiers Class Missions," $41^{\text {st }}$ AIAA Joint Propulsion Conference, AIAA 2005-4271, Tucson, Arizona, July 2005.

${ }^{6}$ Anderson, D., Kamhawi, H., Patterson, M., Pencil, E., Piñero, L., Falck, R., and Dankanich, J., "Status of Propulsion Technology Development Under the NASA In-Space Propulsion Technology Program", $50^{\text {th }}$ AIAA Joint Propulsion Conference, AIAA 2014-3605, Cleveland, Ohio, USA, July 28-30, 2014.

${ }^{7}$ Kamhawi, H., et al., "Overview of Hall Thruster Activities at NASA Glenn Research Center," $32^{\text {nd }}$ International Electric Propulsion Conference, AIAA-2011-339, Wiesbaden, Germany, September 2011.

${ }^{8}$ Kamhawi, H., et al., "Performance and Environmental Test Results of the High Voltage Hall Accelerator Engineering Development Unit," AIAA-2012-3854, 48 ${ }^{\text {th }}$ AIAA Joint Propulsion Conference \& Exhibit, Atlanta, Georgia, July 29 - August 1, 2012.

${ }^{9}$ Dankanich, J., Cardin, J., Dien, A., Kamhawi, H., Netwall, C., and Osborn, M., "Advanced Xenon Feed System (AXFS) Development and Hot-fire Testing," $45^{\text {th }}$ AIAA Joint Propulsion Conference, AIAA 2009-4910, Denver, Colorado, USA, August 2-5, 2009.

${ }^{10}$ Piñero, L., Kamhawi, H., and Drummond, G., "Integration Testing of a Modular Discharge Supply for NASA's High Voltage Hall Accelerator Thruster," $31^{\text {st }}$ International Electric Propulsion Conference, IEPC-2009-275, Ann Arbor, Michigan, September 2009. 